\title{
Em busca do Humanismo: um olhar sobre a visita técnica nos cursos de turismo a partir da teoria crítica em currículo
}

\author{
In search of Humanism: a look into \\ technical visits in toursim courses \\ based on the curriculum critical theory
}

Thiago Rodrigues SCHULZE*

\begin{abstract}
Resumo: No presente artigo objetiva-se analisar uma estratégia de aprendizagem presente nos cursos de Turismo, a visita técnica. Destaca a importância da necessidade de encontrar um olhar humanista para essa estratégia de aprendizagem, construída a partir de aspectos da Teoria Crítica em Currículo. O trabalho é desenvolvido apresentando as características atuais do curso de Turismo e refletindo sobre a visita técnica como estratégia de aprendizagem. Finalmente, apresenta a concepção humanista como alternativa à lógica tecnicista, voltada exclusivamente para o mercado, e o respectivo papel dos educadores nesse processo.
\end{abstract}

Palavras-chave: estratégias de aprendizagem, visita técnica, cursos de Turismo, teoria crítica em currículo

\begin{abstract}
The present article aims at analyzing a learning strategy found in Tourism courses: the technical visit. It highlights the importance of finding a humanistic approach for this learning strategy developed from aspects of the Curriculum Critical Theory. This work presents current characteristics of the Tourism course and considerations on the technical visit as a learning strategy. Finally, this work presents a humanistic conception as an alternative to the technical logic, exclusively market-oriented as well as the professors' roles in the process.
\end{abstract}

Key words: learning strategies, technical visit, Tourism courses, curriculum critical theory *Especialista em Planejamento e Marketing Turístico. Especialista em Docência para
Turismo e Hotelaria. Email: thiagoschulze@hotmail.com

Olhar de professor, Ponta Grossa, 8(1): 51-67, 2005. 
A presente análise surgiu como resultado das reflexões, discussões, atividades e leituras desenvolvidas ao longo de uma disciplina sobre currículo, ministrada em um programa de estudos de pós-graduação em Educação. Além disso, buscou-se lançar um olhar sobre as experiências como aluno e docente nos cursos de Turismo, de forma a compor uma reflexão sobre alguns enfoques da Teoria Crítica em Currículo, a partir de uma experiência prática, especificamente de uma estratégia de aprendizagem utilizada nesses cursos, conhecida como visita técnica.

A justificativa de se buscar uma reflexão sobre currículo em estratégias ou ambientes de aprendizagem nos cursos de Turismo está justamente na "práxis freireana", na qual existe uma comunhão entre a ação e a reflexão, devendo então estender-se a todas as situações ou, melhor dizendo, configurando-se como direito de todos os homens. Aliás, sobre uma dúvida inicial a respeito da validade ou da relevância social de aplicação desse conceito de práxis nos cursos de Turismo, convém relembrar uma citação de Paulo Freire. Nela, o autor indica que "a formação técnico-científica não é antagônica à formação humanista dos homens, desde que a ciência e tecnologia, na sociedade revolucionária, devem estar a serviço de sua libertação permanente, de sua humanização"(FREIRE, 1979, p. 186).

Mesmo tendo o curso de Turismo um caráter predominantemente técnico, nada impede que o mesmo seja encarado sob o prisma da formação humanista. Por isso, aqui entra em cena outro aspecto da teoria de Freire, especificamente a questão da permanência e da mudança. Na maior parte dos casos, como será visto ao longo da reflexão, os enfoques tecnicista e mercadológico têm sido os predominantes nesse cursos, o que implica necessariamente um pensar e agir (práxis) no sentido da mudança.

Buscando um enfoque mais específico dentro do curso de Turismo, o objeto a ser analisado é uma estratégia de aprendizagem muito utilizada nesses curso, conhecida como visita técnica. Surge então o problema de pesquisa, que fica assim definido: como pensar a visita técnica nos cursos de Turismo, a partir dos pressupostos da Teoria Crítica em Currículo?

A reflexão está estruturada em três partes. A primeira, introdutória, faz uma apresentação dos cursos de Turismo e uma reflexão crítica acerca dos enfoques tecnicista e exclusivamente mercadológico de tais cursos; a segunda parte apresenta o material e a forma como foi analisada a visita técnica como estratégia e espaço de aprendizagem; finalmente, a última parte relata os resultados obtidos e a relação e busca pelo enfoque humanista na visita técnica realizada nos cursos de Turismo. 


\section{OS CURSOS DE TURISMO}

A primeira parte, cujo objetivo é fazer uma apresentação rápida dos cursos de Turismo, criticando o enfoque predominantemente tecnicista e mercadológico desses cursos na atualidade, está estruturada em três pontos básicos: a evolução histórica dos cursos de Turismo; o campo do conhecimento em Turismo; e um enfoque mais humano nos cursos de Turismo.

Iniciando a análise do primeiro ponto, especificamente a evolução histórica dos cursos de Turismo, Ansarah (2002) a divide em quatro fases: a primeira fase, na década de 1970, foi marcada pela criação dos primeiros cursos de Turismo, como é o caso da Faculdade Anhembi-Morumbi (atualmente Universidade AnhembiMorumbi); a segunda fase, devido às crises econômicas da década de 1980 , foi marcada pela estagnação da oferta de cursos; a terceira fase, que abrange grande parte da década de 1990 , caracterizou-se pelo grande aumento dos cursos em âmbito acadêmico, bem como pela expansão dos cursos em vários estados brasileiros; a quarta fase, influenciada pela Lei de Diretrizes e Bases (LDB) de 1996, atualmente caracteriza-se por um aumento de propostas flexíveis de cursos, bem como pela regionalização. Apesar da ausência de dados consistentes que comprovem esta hipótese, a experiência profissional do autor e o contato com pesquisadores da área (inclusi- ve com a própria Marília Ansarah, que admite esta tendência), é possível prever o início de uma quinta fase, caracterizada pelo crescente desinteresse em relação aos cursos de Turismo, desinteresse esse que vem ocasionando o fechamento de alguns cursos, em especial daqueles não reconhecidos pelo Ministério da Educação e Cultura (MEC).

Lançando um olhar sobre esta evolução histórica, pode-se levantar alguns indícios que justificam o enfoque predominantemente tecnicista e mercadológico dos cursos de Turismo, especialmente no Brasil. Um indício é o aparecimento recente desses cursos. Diferentemente de áreas tradicionais como a Geografia, a Sociologia e a Filosofia, dentre outras, os cursos de Turismo surgiram no Brasil apenas nos anos 70 , durante o regime militar, quando a educação de forma geral teve ênfase tecnicista, desprezando os aspectos sociopolíticos e culturais que envolvem todas as áreas do conhecimento. Um segundo indício, mencionado inclusive pelo trabalho de Ansarah (2002), cuja pesquisa apresentou os cursos de Turismo existentes no Brasil, é a grande predominância das instituições privadas no que tange à oferta de tais cursos. Um exemplo é o estado de São Paulo, onde somente a USP (Escola de Comunicações e Artes) oferece o curso como instituição pública. Essa escassez de instituições públicas que ofereçam cursos de Turismo traz como conseqüência direta a falta de pesqui- 
sa na área, pois o enfoque das instituições privadas (excetuando-se poucas instituições, como a PUC-Campinas) é somente a preparação de mãode-obra para o mercado de trabalho. Um último indício que merece destaque diz respeito à formação dos docentes em Turismo. Devido ao fato de o turismo ser uma área recente de estudo, não tendo, portanto, tradição acadêmica, é comum encontrar duas categorias de docentes no curso: uma categoria diz respeito aos professores oriundos de áreas tradicionais como Filosofia, História, Sociologia, Direito, etc.; outra está relacionada com profissionais que possuem grande experiência no mercado turístico, e que acabam por lecionar disciplinas correlatas às suas áreas de atuação. Se, por um lado, são valiosas as contribuições tanto dos professores de outras áreas do conhecimento como dos profissionais de mercado, por outro, essa prática por muito tempo desestimulou a formação de professores em turismo. Somente agora é perceptível o crescimento do interesse pela docência por parte daqueles que estudam Turismo.

Finalizando esse olhar sobre a evolução histórica dos cursos, bem como os três indícios que dela emergem (surgimento recente dos cursos durante o regime militar, predominância das instituições privadas e falta de professores), é possível compreender os motivos da predominância dos enfoques tecnicista e mercadológico nos cursos de Turismo, visando (salvo raras exceções) à preparação de mão-de-obra qualificada para o mercado e não estimulando uma reflexão crítica sobre o fenômeno social chamado turismo.

Após a apresentação de um breve panorama histórico dos cursos de Turismo, é preciso fazer uma reflexão sobre o turismo como área de conhecimento. Não se trata, porém, de tecer uma longa discussão em relação à epistemologia do turismo, já que o enfoque do trabalho diz respeito a uma estratégia de aprendizagem utilizada nos cursos. Porém, ao não apresentar alguns pontos de discussão sobre o conhecimento na área de turismo, corre-se o risco de não se compreender a importância da estratégia (visita técnica) dentro do contexto do curso.

Como pode ser acompanhado no primeiro ponto apresentado, o surgimento dos cursos de Turismo no Brasil é recente, datando da década de 1970. Aliás, o estudo do Turismo de forma geral ainda é novo, comparando-se com disciplinas tradicionais como a Matemática, a História, a Antropologia, a Educação, dentre outras. É possível acompanhar as diferenças entre a área de turismo e as disciplinas já consagradas, ao analisar o histórico acadêmico, as comunidades científicas internacionais, as publicações (tanto livros como periódicos), as associações de pesquisa, os eventos acadêmicos realizados para se discutir as novas tendências, o reconhecimento universitário. É possível até traçar um comparativo analisando o 
número de mestres e doutores nessas áreas. Por outro lado, negar a importância atual do turismo na sociedade pós-industrial, é afirmar o desconhecimento de fatos como o $11 \mathrm{de}$ setembro (e depois o 11 de março na Espanha ${ }^{1}$ ), bem como a importância da atividade turística em termos econômicos e sociais para muitos países.

Sendo assim, Trigo consegue retratar a atual situação do turismo como área de conhecimento, ao afirmar que "o turismo é uma das especialidades no extenso campo da ciência" (TRIGO, 1998, p. 163). Porém, isso não quer dizer que o estudo do turismo não seja importante ou que a metodologia para seu estudo deva desprezar a rigorosidade característica da ciência. Aliás, analisando o turismo como um fenômeno social complexo, diversas ciências compõem seu corpo de estudo. É por isso que autores da área, como é o caso de Ansarah (2002) e Trigo (1998), defendem a necessidade de um enfoque transdisciplinar nos cursos, onde se parte de situações-desafio ou problema, e se utilizam diversos campos do conhecimento para a resolução desses problemas ou desafios.

No bojo desta discussão sobre o turismo como área de conhecimento, surge o terceiro ponto a ser analisado, ou seja, a busca de um enfoque mais humanista nos cursos de Turismo. Esse enfoque faz-se necessário sobretudo no atual contexto sócioeconômico, principalmente no Brasil, onde a atividade turística demonstra constantes sinais de crescimento. Para a construção desse enfoque são resgatados alguns princípios de Paulo Freire (1979), apresentados em "Pedagogia do Oprimido", os quais são comparados com a realidade dos cursos em questão.

A justificativa dessa busca pelo humanismo já se faz em um primeiro momento, ao analisar a opinião de Freire em relação à pedagogia humanizadora. Segundo o autor, "não há outro caminho senão o da prática de uma pedagogia humanizadora, em que a liderança revolucionária, em lugar de se sobrepor aos oprimidos e continuar mantendo-os como quase "coisas", com eles estabelece uma relação dialógica permanente" (FREIRE, 1979, p. 60).

Ainda de acordo com o autor, o contrário desta pedagogia humanizadora é a chamada "educação bancária”, em que alguns conteúdos são depositados nos alunos por professores que, em teoria, detêm todo o conhecimento. É possível (infelizmente, até comum) encontrar muitas situações em que a concepção bancária de educação se faz presente nas instituições brasileiras de nível superior. Eis alguns exemplos: quando se formam classes de 120 alunos, transformando as aulas em palestras e

\footnotetext{
${ }^{1}$ Nome dado aos atentados terroristas ocorridos em 11 de setembro de 2001, nos Estados
} Unidos da América, e em 11 de março de 2004, na Espanha.

$$
\text { Olhar de professor, Ponta Grossa, 8(1): 51-67, } 2005 .
$$


inviabilizando a participação dos alunos devido à quantidade, a educação bancária está sendo praticada; quando as faculdades e universidades colocam como objetivos principais (quando não únicos) de seus cursos o treinamento e a preparação para o mercado de trabalho chamado competitivo, a educação bancária está sendo praticada; quando não são abordadas questões como a diversidade cultural dos povos, o que Santos (2001) chamaria de sociodiversidade, também está se praticando a educação bancária.

Em oposição a essa educação bancária, Freire sustenta os pressupostos da educação libertadora. Nas palavras do autor,

o importante, do ponto de vista de uma educação libertadora, e não "bancária", é que, em qualquer dos casos, os homens se sintam sujeitos de seu pensar, discutindo o seu pensar, sua própria visão do mundo, manifestada implícita ou explicitamente, nas suas sugestões e nas de seus companheiros" (FREIRE, 1979, p. 141).

É possível estabelecer uma relação entre o que Freire defende como educação libertadora e as situaçõesdesafio que emergem dos diversos cursos de Turismo (Freire os chamaria de temas geradores). Torna-se importante destacar que esses "temas geradores" ou situações-problema devem levar em consideração as diversas visões de mundo, não somente a visão do mercado que, por ser exclusiva, acaba por tornar-se opressora.

Em última instancia, é neste momento que se faz necessária a emergência do que Freire chamou de "educador problematizador" nos cursos de Turismo. Educadores que, conscientes de seu papel histórico na construção não somente dos conteúdos, habilidades e atitudes a serem dialogadas com seus aprendizes ao longo do curso, mas no sentido humano da construção de uma nova prática em turismo. Uma prática que, baseada na teoria de sua ação, construída por seres humanos, encare a atividade turística como um fenômeno social, cultural e político, e não apenas como uma atividade econômica.

\section{ESTRATÉGIAS DE APRENDIZA- GEM E A VISITA TÉCNICA NOS CURSOS DE TURISMO}

Após a reflexão sobre os cursos de Turismo dentro de um contexto geral, torna-se necessário analisar o objeto de pesquisa, especificamente a visita técnica como estratégia de aprendizagem no curso de Turismo. O material utilizado para a análise está ligado tanto à bibliografia referente à temática quanto à experiência profissional do autor como docente em cursos de Turismo. Em relação à metodologia adotada, devido às características do trabalho desenvolvido, conforme apresentado inicialmente, ao invés de procurar uma denominação metodológica que melhor se encaixa- 
ria nesta reflexão, é adequada a utilização de um conceito de Donald Schon (apud NÓVOA, 1992), conhecido como "reflexão na ação". Com base nesse conceito, o autor, enquanto profissional reflexivo, procura investigar, refletir e questionar a prática de determinada estratégia de aprendizagem em determinado curso. Sendo assim, ao longo da análise, a teoria se une à prática, com o objetivo de compreender os aspectos pertinentes à visita técnica nos cursos de Turismo.

O conceito de estratégia de aprendizagem, neste trabalho, leva em consideração o enfoque de Abreu \& Masetto. De acordo com os autores:

Estratégias são os meios que o professor utiliza em sala de aula para facilitar a aprendizagem dos alunos, ou seja, para conduzi-los em direção aos objetivos daquela aula, daquele conjunto de aulas ou daquele curso. Procurando conceituar de maneira mais formal, podemos dizer que as estratégias para a aprendizagem constituem-se numa arte de decidir sobre um conjunto de disposições, de modo a favorecer $o$ alcance dos objetivos educacionais pelo aprendiz. (ABREU; MASETTO, 1990, p. 50).

A partir dessa afirmação, surgem alguns aspectos que podem ser utilizados como categorias-base para a caracterização da visita técnica como estratégia de aprendizagem nos cursos de Turismo.
Um primeiro aspecto a ser analisado diz respeito ao objetivo da estratégia. A determinação do objetivo da estratégia dá sentido aos outros aspectos que emergem a partir da reflexão de Abreu \& Masetto (op cit). Sem o objetivo da estratégia definido, corre-se o risco de pensá-la como um fim em si mesma, desprezando os conteúdos, habilidades e atitudes que se deseja trabalhar em determinado momento.

O segundo aspecto relevante que emerge da reflexão dos autores é a abrangência das estratégias de aprendizagem, os quais podem abarcar diferentes níveis, tais como uma única aula, um determinado conjunto de aulas que aborde um assunto específico, o curso como um todo.

Dentro desta reflexão, cabe ainda um terceiro aspecto, especificamente a viabilidade. Após pensar a questão dos objetivos e os diferentes níveis de abrangência, é preciso enfatizar a necessidade de se verificar a possibilidade de implantação de determinada estratégia. Dentro dessa lógica, cabe um olhar sobre os espaços a serem utilizados (salas de aula, laboratórios, ambientes profissionais, dentre outros), os recursos (computadores, giz e lousa, softwares específicos, retroprojetores, etc. ), a quantidade de alunos, o horário de aula (matutino, vespertino ou noturno), a disponibilidade do professor e da instituição. Enfim, cabe pensar como a estratégia será implantada. Além disso, é impor- 
tante ressaltar que estratégias que envolvam um conjunto de aulas ou o curso como um todo são mais complexas de serem implantadas. O mesmo ocorre com as estratégias interdisciplinares, pois dependem da atuação conjunta de dois ou mais professores, necessitando, portanto, de um planejamento conjunto no qual fique claro quais serão os objetivos a serem atingidos e como eles serão trabalhados.

Ao refletir sobre as estratégias de aprendizagem, é perceptível o surgimento de algumas vantagens tanto para os educadores como para os aprendizes. No caso dos professores, a busca por novas estratégias de aprendizagem resulta em dinamismo para a disciplina, para o curso e, principalmente para os professores, pois eles passam a buscar novos conteúdos, novas formas de abordagem dos próprios conteúdos, habilidades e atitudes a serem desenvolvidas. Além disso, o planejamento das estratégias de aprendizagem reduz a insegurança do professor frente a seus alunos, evitando situações de improviso ou a perda dos objetivos de aprendizagem.

Por outro lado, a busca por novas estratégias de aprendizagem também traz vantagens para os alunos. Pelo fato da variação de estratégias trazer uma nova dinâmica para o curso, os alunos acabam por sentirem-se mais motivados. Além disso, a variação nas estratégias é capaz de atender às diferenças individuais dos alunos. Um exemplo: um grupo de alunos consegue assimilar melhor determinado conteúdo, a partir de uma aula expositiva dialogada, ao passo que outros alunos obtêm melhores resultados em dinâmicas dr grupo. A partir do momento em que o docente varia as estratégias de aprendizagem, é possível contemplar tanto os alunos que preferem a aula expositiva como os que preferem as dinâmicas de grupo.

Finalmente, um último aspecto cabe aqui ser mencionado: a relevância de se ter o domínio da estratégia. Nesse sentido, é importante um cuidado por parte do professor, pois uma estratégia mal aplicada pode gerar desinteresse pela aula (ou pior, pelo curso) por parte dos alunos. Conseqüentemente, os objetivos de aprendizagem podem não ser atingidos, e o próprio docente pode frustrar-se. Por outro lado, não existem receitas prontas para o sucesso da aplicação de tais estratégias. O que existe são publicações, como a de Veiga (1991), que apresenta algumas estratégias utilizadas em contextos específicos, como a leitura de um texto ou estudo do meio. Portanto, a utilização adequada das estratégias requer, acima de tudo, treino (onde se aprende inclusive com alguns fracassos) e bom senso para perceber as características do grupo (no caso, a classe) em que a estratégia será aplicada.

Conforme a própria denominação, a visita técnica consiste em uma atividade no qual os alunos dirigem-se a um local específico, orientados pelo 
professor, com o objetivo de se desenvolver um conjunto determinado de aprendizagens. Em turismo, tais aprendizagens incluem visitas de um dia a parques, museus, eventos como feiras e congressos, aeroportos, empresas relacionadas com a área de turismo, etc. É comum encontrar também visitas a localidades. Estas, mais complexas, dependendo do objetivo de aprendizagem, podem variar quanto ao tempo de duração, sendo que algumas visitas técnicas podem durar até uma semana. Porém, atualmente é comum a prática de visitas mais curtas, devido ao momento econômico atual do país.

Sob o prisma da aprendizagem, a visita técnica em Turismo pode ser considerada uma técnica que possibilita o desenvolvimento de conteúdos, habilidades e atitudes específicas fundamentais para a área de turismo, tais como: a possibilidade de se acompanhar o fenômeno turístico in loco, o que se torna indispensável, já que o turismo essencialmente consiste no deslocamento de pessoas de um lugar para outro; a visita técnica coloca o aluno em contato direto com a práxis (no sentido freireano), já que esse aluno pode acompanhar a ação baseado nas reflexões e na teoria desenvolvida antes, durante e até em um momento posterior à visita técnica; finalmente, a visita técnica, a partir da práxis citada anteriormente pode gerar propostas que visem à mudança de certos aspectos observados, ou então, em casos de sucesso, que le- vem o aluno a refletir sobre a possibilidade da busca de soluções para outros contextos a partir da visita realizada.

Assim como outras estratégias de aprendizagem, existe a necessidade de se pensar no planejamento da visita técnica em turismo, levando em consideração os objetivos de aprendizagem, o local escolhido, o número de alunos, a disponibilidade de recursos, as disciplinas (e, conseqüentemente, os professores) envolvidas e o apoio da instituição. Apesar desse planejamento não ser um instrumento fechado, Masetto (2003) chama atenção para três cuidados básicos ao pensar a visita técnica como estratégia de aprendizagem. São eles: a integração com o assunto estudado no momento; a preparação conjunta com os alunos; a conscientização de que a visita técnica não se esgota nela mesma. Sobre o primeiro cuidado a ser tomado, é preciso destacar que ele possui relação com a práxis já mencionada, na qual toda ação necessita de uma reflexão e de uma teoria que a justifique. No segundo aspecto, o planejamento conjunto da atividade é justificado pelos mesmos motivos da necessidade de variar as técnicas de aprendizagem, ou seja, a motivação por parte dos alunos e dos professores, o dinamismo do curso, etc. Finalmente, após definir-se o que é e como será desenvolvida a visita técnica, convém ressaltar que existe a necessidade de trabalho posterior à visita, quando serão utilizados os materiais 
preparados pelos alunos, tais como relatórios, vídeos, fotografias, folhetos recolhidos no local, entrevistas, entre outros. Esse trabalho pós-visita faz-se necessário para que se atinjam os objetivos de gerar propostas de transformação ou, mesmo, de encontrar pontos positivos, nos casos considerados de sucesso.

Apesar da brevidade desta apresentação sobre a visita técnica e suas características básicas, convém ressaltar que, na maioria dos casos, pouco se reflete sobre a importância da visita técnica como estratégia de aprendizagem nos cursos de Turismo. Geralmente ela é encarada apenas como formalidade a compor o currículo desses cursos. Além disso, são raros os casos nas instituições brasileiras de ensino superior em que os cuidados propostos por Masetto (2003) são contemplados. É comum encontrar situações em que a visita técnica não é planejada em conjunto com os alunos, os quais, muitas vezes, acabam por encarar a visita como entretenimento e oportunidade de conhecer locais novos. Não se quer dizer, com isso, que esses dois aspectos não possam ser contemplados. Porém, a partir do momento em que existe um planejamento conjunto, um trabalho que envolva um "antes", um "durante" e um "pós-visita técnica", integrado ao que está sendo desenvolvido no curso como um todo, surgem as vantagens já descritas em relação às estratégias de aprendizagem. Outro aspecto que merece destaque é a predominância do enfoque tecnicista e mercadológico da visita técnica (reproduzindo as características do curso de Turismo, como visto no início), quando se visita um determinado local, seja um parque, um evento ou até um município, e se analisa apenas o "como fazer": como atender um cliente, como elaborar um determinado plano, etc. Dessa forma, o turismo não é encarado como um fenômeno inserido num contexto sóciocultural e político mais amplo.

Por isso, surge então a necessidade de reconceptualização da visita técnica como prática curricular nos cursos de Turismo, indo em busca de um sentido mais humanista não somente para a estratégia em si, mas para o curso como um todo.

\section{EMBUSCADEUMOUTROOLHAR SOBREAVISITATÉCNICAEMTU- RISMO}

Após a análise da visita técnica como estratégia de aprendizagem em um curso de Turismo, como resultado emerge a necessidade da busca pelo humanismo, a qual acarreta um outro olhar fundamentado nas reflexões de curriculistas críticos como Domingues, Apple, Giroux e Freire, integrando-se algumas idéias desses autores ao objeto pesquisado.

Conforme mencionado anteriormente, destaca-se a necessidade de reconceptualização da visita técnica como prática curricular. Nesse sentido, o trabalho de José Luiz Domingues 
(1988), que pesquisou o cotidiano de uma escola de $1^{\circ}$ grau em Goiânia, torna-se fundamental, pois o autor foi um dos pioneiros a utilizar, no Brasil, a palavra reconceptualização (a partir de James McDonald) em currículo. De acordo com o autor, é preciso encarar o fazer currículo

mais como um empreendimento humanístico, uma situacionalidade educador-educando, dialógica e problematizadora, mediatizado pela proposta cultural de uma sociedade que também é temporal e têm um ritmo histórico, do que como um conjunto de problemas técnicos a ser resolvido dentro de um esquema teórico que se pretende impor de fora para dentro. (DOMINGUES, 1988, p. 20).

A partir desse novo "fazer currículo", é possível perceber a necessidade de mudança ao se pensar a visita técnica como estratégia de aprendizagem nos cursos de Turismo. Domingues (1988), em seu "fazer currículo", indica a importância do humanismo, seja na relação educadoreducando, seja na proposta cultural de uma sociedade temporal e histórica. O mesmo ocorre na visita técnica em Turismo, pois sendo ela uma prática curricular como todas as outras, não se pode descartar a dialogicidade entre educador em turismo e educando em turismo, e entre educandos em turismo. Além disso, o turismo também influencia e é influenciado pelo contexto social maior, temporal e histórico. Percebe-se, então, a necessidade de não encarar a visita técnica como mera atividade a compor o currículo do curso de Turismo, mas de refletir sobre a importância dessa visita no citado contexto maior. Por outro lado, é perceptível, na fala de Domingues (1988), a prevalência do paradigma dinâmico-dialógico, baseado no pensamento neo-marxista. Conforme o autor, esse paradigma está assentado em três premissas básicas, que são as seguintes:

a) o currículo não pode ser separado da totalidade do social, deve ser historicamente situado e culturalmente determinado;

b) o currículo é um ato inevitavelmente politico que objetiva a emancipação das camadas populares;

c) a crise que atinge o campo de currículo não é conjuntural, ela é profunda e de caráter estrutural. (DOMINGUES, 1988, p. 37).

As premissas relatadas por Domingues servem para reforçar o que este trabalho defende como educação em turismo. No entanto, a partir dessas premissas emerge a necessidade de uma reflexão sobre algumas idéias de curriculistas críticos influenciados pelo pensamento neo-marxista: neste momento, Apple, especificamente; e, em seguida, Giroux.

Um primeiro aspecto encontrado nas reflexões de Apple, é a questão 
da hegemonia e da ideologia. De acordo com o autor, a hegemonia "referese antes, a um conjunto organizado de significados e práticas, ao sistema central, efetivo e dominante de significados, valores e ações que são vividos" (APPLE, 1982, p. 14). Sobre o segundo aspecto, Apple indica que "a ideologia lida sempre com a legitimação, o conflito de poder e um estilo especial de argumentação" (id ibid, p. 36). Esses dois aspectos são claramente encontrados em turismo. Atualmente, o que acaba por ser hegemônico em turismo é a lógica de mercado, onde o fator a ser valorizado é o capital, ou seja, os efeitos do turismo sobre a balança comercial, a geração de renda, a entrada das grandes redes hoteleiras internacionais no Brasil, etc. Por outro lado, a legitimação, o conflito de poder e o estilo de argumentação citados por Apple, ao se referir à ideologia, também encontram espaço no turismo. Aqui entram outros exemplos, como é o caso da conservação ambiental em detrimento da construção de uma nova rodovia ${ }^{2}$, a cobrança de altas taxas e a restrição ao número de turistas que podem visitar determinada localidade (como Fernando de Noronha-PE), a remoção de comunidades locais para a implantação de um novo resort $^{3}$ (como no município de
Mata de São João-BA, onde foi implantado o megaresort Costa do Sauípe), dentre outros exemplos.

$\mathrm{O}$ que cabe ressaltar, neste momento, é a influência dessas questões maiores no contexto das escolas. Conforme as palavras de Apple, (1982, p. $73)$ "o currículo nas escolas responde aos recursos ideológicos e culturais de alguma parte e os representa". E esses recursos ideológicos e culturais de alguma parte são representados, de forma prática, nos contextos escolares, a partir da opção por determinados conteúdos e o abandono de outros, assim como pela forma de utilização das estratégias de aprendizagem. Como já fora apontada a lógica de mercado como hegemônica na área de turismo em geral, esta lógica há de influenciar também os cursos e, conseqüentemente, os objetivos de aprendizagem e as formas de atingir esses objetivos (a partir das estratégias de aprendizagem). Por outro lado, não se quer concluir aqui, precipitadamente, o fato de que os professores em turismo têm o claro objetivo de apresentar a área como estritamente econômica (alguns até possuem esse objetivo). Mas é ilusão negar que existe uma forte influência do enfoque mercadológico sobre os cursos, inclusive sobre a estratégia analisada neste momento, ou seja, a visita técnica. Aliás,

\footnotetext{
${ }^{2}$ Um caso brasileiro referente a essa questão foi a construção da Nova Imigrantes, ligando os municípios da Grande São Paulo ao litoral.

${ }^{3}$ Grande hotel de lazer.

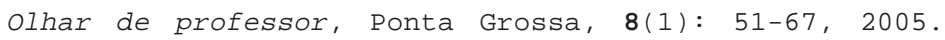


Apple continuou a ressaltar essa característica, ao (re)pensar anos mais tarde sua obra prima "Ideologia e currículo". Segundo o autor,

embora nossas instituições educacionais de fato operem para distribuir valores ideológicos e conhecimento, sua influência não se resume a isso. Como sistema institucional, elas também ajudam, em última análise, a produzir o tipo de conhecimento (como se fosse um tipo de mercadoria) necessário à manutenção das composições econômicas, políticas e culturais vigentes (APPLE in MOREIRA e SILVA, 2000, p. 45).

Tal reflexão de Apple condiz exatamente com a prática atual da visita técnica nos cursos de Turismo. Ou seja, se essa é uma estratégia de aprendizagem que visa a contribuir para a formação dos educandos em Turismo, a partir do momento em que ela contempla unicamente a visão tecnicista do "como fazer" e o enfoque mercadológico como único a ser levado em consideração, a atual visão em relação à área pode acabar sendo reproduzida como única possível.

Afirmar que a visão mercadológica e tecnicista presente na estratégia de aprendizagem visita técnica é a única possível, tem implicações totalmente diferentes da afirmação "pode ser reproduzida como única possível”. Afirmar que a visão de mercado é a única possível traz imediatamente uma visão de imutabilidade e permanên- cia. E, sendo imutável e permanente, não haveria sentido em se lançar um olhar crítico sobre essa prática. Por outro lado, a segunda afirmação oferece espaço para uma indagação: se a visita técnica pode reproduzir a lógica de mercado como única possível, seria possível, então, mudar o enfoque atual dessa mesma estratégia?

Um dos curriculistas críticos atuais a trabalhar o conceito de possibilidade é Giroux, que, aliás, foi fortemente influenciado pelas idéias de Paulo Freire. De acordo com o autor, "para que a política radical se torne um projeto político viável, ela precisa desenvolver um discurso que combine a linguagem da análise crítica com a linguagem da possibilidade" (GIROUX, 1997, p. 27). A partir dessa afirmação é possível perceber a relação com a área pedagógica e que Giroux também é contrário ao que Cortella (2002) chamaria de pessimismo ingênuo na educação. Em seu livro "Os professores como intelectuais", Giroux fundamenta o discurso da esperança e possibilidade utilizando dois autores, Eagleton e Welch. Conforme Giroux,

Eagleton e Welch respectivamente desenvolvem e demonstram a importância de tornar o discurso da ética e da esperança, por um lado, e a luta em andamento para o desenvolvimento de esferas públicas democráticas dentro e fora das escolas, por outro, aspectos centrais de uma teoria 
educacional crítica. Enquanto Eagleton questiona e reconstrói criticamente o relacionamento entre crítica social e a esfera pública, Welch fornece os referenciais morais que ligam a teoria e prática às lutas políticas e pedagógicas correntes com grupos oprimidos e subordinados, (GIROUX, 1997, p. 258).

Esse é justamente o objetivo desta reflexão, ou seja, fazer com que o discurso da ética, da esperança e da possibilidade seja trabalhado no curso de Turismo a partir de práticas já inerentes ao mesmo, como a estratégia de aprendizagem visita técnica,e não como algo imposto de fora para dentro. E, aqui, cabe uma pergunta: sobre qual ética, qual esperança e qual possibilidade se está falando? Sobre a necessidade de se pensar o turismo como um fenômeno social, cultural e político mais amplo, inserido em uma esfera democrática, em detrimento da visão reducionista da lógica do mercado. É importante destacar que o exercício dessa lógica democrática perpassa o que Apple \& Beane (2001) chamam de "escolas democráticas". Além disso, Apple e Beane (2001) mencionam o currículo democrático, indicando que "como a democracia envolve o consentimento consciente das pessoas, um currículo democrático enfatiza o acesso ao leque de informações e o direito dos que têm opiniões diferentes se fazerem ouvir" (op cit, p. 26).

Esse direito dos que têm opiniões diferentes se fazerem ouvir acaba por tornar-se imprescindível para a reconceptualização da visita técnica em turismo, rumo a uma estratégia de aprendizagem democrática. Mas quem seriam aqueles que possuem opiniões diferentes? São justamente os que se opõem a uma lógica reducionista de mercado. Podem ser eles membros de minorias étnicas, raciais e sexuais; podem ser também membros de comunidades receptoras onde o turismo está se desenvolvendo e são obrigados a deixar seus lugares de origem, devido à implantação de novos complexos hoteleiros; enfim, são todos aqueles que não se enquadram ou não concordam com a política de mercado sendo vista como única alternativa possível. E de que forma a visita técnica pode colocar em prática o exercício da democracia? Longe de tornar a estratégia de aprendizagem algo padronizado, não adaptável a diferentes contextos, é importante planejar a estratégia considerando, além dos objetivos de aprendizagem, a voz das minorias, bem como de alguns personagens do local onde se queira visitar. Esse planejamento em conjunto é importante para se pensar uma visita técnica democrática. Porém, existe um último fator imprescindível para se pensar uma visita técnica mais democrática, conseqüentemente, mais humista: a comunicabilidade.

De acordo com Freire (1996, p. 140), "uma das tarefas essenciais da escola, como centro de produção sis- 
temática de conhecimento é trabalhar criticamente a inteligibilidade das coisas e dos fatos e sua comunicabilidade". A comunicabilidade é, na maior parte das vezes, um fator esquecido nas visita técnicas em turismo. Geralmente realiza-se a visita, tiram-se as conclusões e, talvez devido à forte influência do fator competitividade na lógica do mercado, essas conclusões não são comunicadas ao local ou localidade visitada. Buscando um enfoque mais democrático e, conseqüentemente, mais humanista, é possível pensar em várias maneiras de se comunicar as reflexões trabalhadas ao longo da visita técnica. Uma alternativa seria a realização de um pequeno seminário no local ou localidade visitada, onde os alunos poderiam expor seus relatórios (já com as conclusões), tendo a oportunidade de dialogar com os "personagens locais", buscando soluções em conjunto para os problemas encontrados. Outra alternativa seria a realização do seminário na própria instituição, porém, convidandose representantes do lugar estudado.

Portanto, um resultado demonstrado por esta reflexão diz respeito ao fato de que seja através das formas apresentadas, seja por outra alternativa encontrada, é um compromisso ético dos educadores e educandos em turismo trabalhar criticamente os dados obtidos durante a visita técnica e sua respectiva comunicação. É justa- mente a partir de pequenas atitudes, como as mencionadas, que serão dados passos rumo à humanização da visita técnica como estratégia de aprendizagem nos cursos de Turismo.

\section{CONSIDERAÇÕES FINAIS}

Quando o sociólogo em educação Almerindo Janela Afonso esteve na PUC-SP ${ }^{4}$, proferiu uma palestra intitulada "A crise na escola e a emergência do não escolar: para uma crítica sociológica às novas apropriações da educação informal e não formal". Durante a palestra, Afonso (2004) refletiu sobre o que seria esse não escolar: um fator que não é contra a escola, mas contrário a formas de educação escolar arraigadas ao valho paradigma escolar (salas de aula, professor como único detentor do saber, etc.). Além disso, apresentou a importância de outros lugares, além da escola, como espaços de educação não formal e informal. Defendeu também a educação não formal e informal como conquistas populares. Surge então a questão: qual seria a relação entre a palestra de Afonso e a conclusão sobre a necessidade da busca pelo humanismo em uma estratégia de aprendizagem, especificamente a visita técnica nos cursos de Turismo?

Convém ressaltar que Afonso (2004) chamou atenção para dois aspectos atuais em que, precipitada-

\footnotetext{
${ }^{4}$ Em 19 de março de 2004
}

Olhar de professor, Ponta Grossa, 8(1): 51-67, 2005. $\overline{65}$ 
mente, atribui-se a culpa às escolas: é o caso das crises econômicas e o desemprego. Essa situação é freqüente nos cursos de Turismo no Brasil. Tratando-se do pequeno crescimento da atividade turística no Brasil, é comum o mercado atribuir a culpa desse baixo crescimento ao despreparo dos profissionais da área. E a culpa desse despreparo cai diretamente sobre as instituições que oferecem cursos de Turismo, afirmando-se que as mesmas não preparam os profissionais para o mercado chamado "competitivo". É bem verdade que os turistas internacionais são exigentes em relação ao atendimento e à oferta de produtos e serviços. Por outro lado, esses mesmos turistas, já cansados do atendimento estandartizado (um exemplo é a rede McDonald's), estão procurando os poucos destinos que ainda preservam suas características históricoculturais. Sobre o desemprego, o mercado - baseado no discurso da competitividade - indica que os profissionais de turismo que estão desempregados foram mal formados ou então não entenderam bem o Life Long Learning, ou seja, a educação continuada. É por não concordar com essa apropriação mercadológica dos termos educação não formal e informal que Afonso (2004) defende uma crítica sociológica a essa emergência do não escolar, onde a visita técnica em turismo está inserida.

Finalmente, é aqui que o caminho a ser trilhado pelo educador em turismo se divide em suas escolhas: assu- mir que a única lógica possível nos cursos de Turismo é a mercadológica ou, munidos do discurso da esperança e da possibilidade, seguir em busca de uma práxis que valorize o aspecto humanista como objetivo principal da educação. O presente trabalho, longe de trazer conclusões definitivas sobre a estratégia de aprendizagem nos cursos de Turismo, pelo menos indica a escolha tomada por este educador.

\section{REFERÊNCIAS}

ABREU, M. C.; MASETTO, M. O professor universitário em aula: prática e princípios teóricos. 8. ed. São Paulo: MG Ed. Associados, 1990.

AFONSO, A. J. A crise na escola e a emergência do não-escolar: para uma crítica sociológica às novas apropriações da educação informal e não-formal. São Paulo, PUC-SP, 19 mar. 2004. (Palestra).

ANSARAH, M. G. R. Formação e capacitação do profissional em turismo e hotelaria: reflexões e cadastro das instituições educacionais no Brasil. São Paulo: Aleph, 2002.

APPLE, M. W. Ideologia e currículo. Tradução de Carlos E. F. Carvalho. São Paulo: Brasiliense, 1982.

. Repensando ideologia e currículo. In: MOREIRA, A. F. B.; SILVA, T. T. (Orgs.). Currículo, cultura e sociedade. Tradução de Maria Aparecida Baptista. 4. ed. São Paulo: Cortez, 2000. .; BEANE, J. A. Escolas demo-

cráticas. 2. ed. Tradução de Dinah de 
Abreu Azevedo. São Paulo: Cortez, 2001.

CORTELLA, M. S. A escola e o conhecimento: fundamentos epistemológicos e políticos. 6. ed. São Paulo: Cortez/IPF, 2002.

DOMINGUES, J. L. O cotidiano da escola de $1^{\circ}$ grau: o sonho e a realidade Goiânia, CEGRAF/UFG. São Paulo: EDUC, 1988

FREIRE, P. Pedagogia do oprimido. 7. ed. Rio de Janeiro: Paz e Terra, 1979.

Pedagogia da autonomia: saberes necessários à prática educativa. São Paulo: Paz e Terra, 1996.

GIROUX, H. A. Os professores como intelectuais: rumo a uma pedagogia crítica da aprendizagem. Tradução de Daniel Bueno. Porto Alegre: Artes Médicas, 1997.

MASETTO, M. T. Competência pedagógica do professor universitário. São Paulo: Summus, 2003.

SANTOS, M. Por outra globalização: do pensamento único à consciência universal. 7. ed. Rio de Janeiro: Record, 2001.

SCHON, D. Formar professores como profissionais reflexivos. In: NÓVOA, A. (Coord.). Os professores e sua formação. Lisboa: Publicações Dom Quixote, 1992.

TRIGO, L. G. G. A sociedade pós-industrial e o profissional em turismo. Campinas: Papirus, 1998.

VEIGA, I. A (Org.) Técnicas de ensino: por que não? Campinas: Papirus, 1991

Encaminhado em 14/02/05

Aceito em 25/04/05

Olhar de professor, Ponta Grossa, 8(1): 51-67, 2005. $\overline{67}$ 